\title{
Potential role of apolipoprotein B/A1 ration in obese and non-obese female patients of coronary artery disease
}

\author{
Sunita Mahto', Suman Bala Sharma², Shridhar Dwivedi², Mani Sethi ${ }^{3}$, Rahul Saxena ${ }^{4}$ \\ ${ }^{1}$ Assistant Professor, Department of Biochemistry, Indira Gandhi Medical College, Shimla, H.P, ${ }^{2}$ Professor, Department of Biochemistry, \\ University College of Medical Sciences, New Delhi, ${ }^{3}$ Research Scholar, Department of Biochemistry, University College of Medical Sciences; \\ New Delhi, ${ }^{4}$ Assistant Professor, Department of Biochemistry, SAHS, Sharda University, Greater Noida, U.P. 201036
}

Background: Obesity and hyperlipidemia are considered to be risk factor for cardiovascular diseases. Many patients who develop coronary artery disease (CAD) are non obese and have normal lipoprotein cholesterol. Assessment of apolipoproteins can improve future risk of cardiovascular complications. Aims and Objectives: We have investigated effect of weight in relation with lipoprotein and apolipoprotein levels as efficient marker of CAD in North Indian females. Materials and Methods: The study population consist of 90 subjects categorized into three groups: Group I: Healthy controls; Group 2: Non obese patients of CAD and Group 3: Obese patients of CAD ( $n=30$ each group). Serum lipid profile along with apolipoprotein $B$ and $A 1$ were measured and apolipoprotein B/A1 ratio were calculated. Results: Total cholesterol and triglycerides levels were significantly high in obese patients as compared to non-obese and controls. LDL-C and HDL-C were altered insignificantly $(p<0.1)$ in Group 2 and Group 3 as compared to Group 1. Apo B and apo A1 were significantly high in obese and non-obese CAD patients as compared to controls whereas insignificant difference was observed ( $p<0.1$ ) when Group 3 patients were compared with Group 2. ApoB/Apo A1 ratio was increased significantly $(p<0.01))$ in patient groups as compared to controls. Conclusion: Although LDL-C and HDL-C were normal in subjects of CAD, increase in Apo B, A1 and its ratio authenticates the fact that these markers are more efficient in detection of CAD risk in obese and non obese patients than conventional lipid profile parameters.

Key words: Apolipoprotein B, Apolipoprotein A1, Lipid profile, Coronary heart disease

\section{INTRODUCTION}

Coronary artery disease (CAD) remains the leading cause of morbidity and mortality in all over the world despite major advances in treatment and prevention. The overall figure of $\mathrm{CAD}$ in the population represents approximately a 10 folds increase in the prevalence of CAD in urban India during the last 40 years. ${ }^{1-3}$ It has been well predicted that by the year 2020 there would be an almost $75 \%$ increase in the global cardiovascular disease burden, and thus, received much attention for early prediction of CAD.., 5

Obesity is one of the reasons which is more prevalent in men until 45 years and in women after that age. ${ }^{6}$ The risk of cardiovascular events is increased especially in subjects with central obesity because of the concomitance of hyperlipdemia or other risk factors. ${ }^{7}$ In fact the metabolic syndrome, defined by the presence of three or more of risk factors which includes central obesity. ${ }^{8}$ However hyperlipidemia linked cardiovascular risk increase cannot be explained in non obese patients. The Apolipoproteinrelated mortality risk (AMORIS) studies were published demonstrating that the concentrations ofapolipoprotein B (ApoB) and apolipoprotein A1 (Apo A1) as well as the ratio of Apo-B/Apo A1 improved prediction of $\mathrm{CHD}$ risk. ${ }^{9}$ Whether apolipoproteins provide any additional predictive informationover and above the usual lipid measurements remains controversialto date. Some early 
case-control studies found Apo-B andApoA-I to be better predictors of coronary heart disease (CHD) than the usual lipids. ${ }^{10,11}$ This idea was supported by several cohort studies. ${ }^{12,13}$ However other prospective studies did not confirm these findings. ${ }^{14,15}$ In the present study, we therefore have investigated the role of Apo-B, Apo $\mathrm{A} 1$ and $\mathrm{Apo} B / \mathrm{A} 1$ ratio in relation to central obesity and lean subjects of CAD.

\section{MATERIALS AND METHODS}

The present study was done in ninety female subjects of age between 30-60 years comprising thirty healthy controls and sixty patients of coronary artery disease admitted in medical wards and/or coronary care unit of University College of Medical Sciences and Guru Teg Bahadur Hospital. Control group included people without hypertension, diabetes mellitus, obesity and hypothyroidism. All the subjects were matched for age and informed consent was taken from all subjects. Study was approved by ethical committee of University College of Medical Sciences, Delhi. Ninety subjects were divided into Group 1 consisting of 30 healthy controls, Group 2 consisting of 30 obese patients of coronary artery disease, Group 3 consisting of 30 nonobese patients of coronary artery disease. Central obesity was defined as waist circumference of $>80 \mathrm{cms}$ in females. Measurement was taken at navel level for central obesity and $\mathrm{CAD}$ was defined on the basis of history, clinical examination, ECG findings, elevated cardiac enzymes and troponins.

Four $\mathrm{ml}$ venous blood was withdrawn under aseptic condition within $12 \mathrm{hrs}$ of admission. Then one $\mathrm{ml}$ of venous blood was transferred in vacutainer containing sodium fluoride in fasting state for plasma glucose. Plasma glucose level was estimated using standard method. Rest $3 \mathrm{ml}$ of venous blood was transferred in plain vacutainer. Sample was centrifuged at $3000 \mathrm{rpm}$ for 10 minutes for serum separation. Serum was collected and separated into two portions. First portion was analysed for lipid profile on the same day of collection using standard methods. Second portion was stored at $-70^{\circ} \mathrm{C}$ for measurement of apolipoproteins. Apolipoproteins B, A1 were done using immunoturbidity method (Randox kit) and ApoB/A1 ratio was calculated.

\section{Statistical analysis}

The data from both the study group subjects and controls were expressed as Mean \pm SD and comparison was made between study group and control group by using one way ANOVA with two Turkey's test at 5\% significance level.

\section{RESULTS}

As shown in Table 1, all the groups were matched for age. There was no statistically significant difference of age in group 2 (non-obese) and group 3 (obese) as compared to group 1 (control). Waist circumference was highly significant $(\mathrm{p}<.001)$ in group 3 (obese) as compared to group 2 and group 1 (controls). Systolic and diastolic blood pressure were significant in group 2 (non-obese) and group 3 (obese) as compared to group 1 (controls). Fasting blood sugar in group 2 (non-obese) and group 3 (obese) was significantly higher as compared to group 1 (controls).

Serum total cholesterol $(\mathrm{TC})$ was significant $(\mathrm{p}<.01)$ in group 3 (obese) as compared with controls whereas TC was found insignificant in obese as compared to nonobese(Table 2). Insignificant difference was also found for HDL-C and LDL-C among the study groups (Table 2).TG levels were found highly significant $(\mathrm{p}<.001)$ in group 3 (obese) as compared to the group 2(non obese) and group 1 (controls), whereas insignificant levels were found in group 2 as compared to group 1(Table 2).

The level of Apo B was found significantly high $(\mathrm{p}<.001)$ in group 2 (non-obese) and group 3 (obese) as compared to group 1 (controls), whereas insignificant level was found in obese group as compared with non-obese group (Table 3 ). Level of Apo-A1 was found significantly lower $(\mathrm{p}<.001)$

\begin{tabular}{|c|c|c|c|}
\hline Parameter & $\begin{array}{l}\text { Group I } \\
(n=30)\end{array}$ & $\begin{array}{c}\text { Group II } \\
(n=30)\end{array}$ & $\begin{array}{c}\text { Group III } \\
(n=30)\end{array}$ \\
\hline Age (years) & $54.3 \pm 6.75$ & $49.00 \pm 9.48$ & $53.1 \pm 12.40$ \\
\hline $\begin{array}{l}\text { Waist circumference } \\
(\mathrm{cm})\end{array}$ & $74.37 \pm 4.15$ & $75.5 \pm 4.5$ & $96.2 \pm 10.9^{b, c}$ \\
\hline $\begin{array}{l}\text { Systolic blood } \\
\text { pressure }(\mathrm{mmHg})\end{array}$ & $114 \pm 4.31$ & $132.93 \pm 32.0^{a}$ & $150.80 \pm 32.24^{b}$ \\
\hline $\begin{array}{l}\text { Diastolic blood } \\
\text { pressure }(\mathrm{mmHg})\end{array}$ & $74.7 \pm 3.64$ & $96.97 \pm 20.73^{a}$ & $103.90 \pm 28.47^{b}$ \\
\hline $\begin{array}{l}\text { Fasting blood sugar } \\
(\mathrm{mg} / \mathrm{dl})\end{array}$ & $95.67 \pm 17.21$ & $135.90 \pm 45.62^{\mathrm{a}}$ & $135.67 \pm 42.62^{\mathrm{b}}$ \\
\hline
\end{tabular}

Where, ${ }^{a}$ Group 1 vs. Group 2 ( $\left.p<.001\right)$, ${ }^{\text {GGroup }} 1$ vs. Group 3 (p<.001), 'Group 2 vs. Group $3(p<.001)$

\begin{tabular}{|c|c|c|c|}
\hline Parameter & $\begin{array}{l}\text { Group I } \\
(n=30)\end{array}$ & $\begin{array}{c}\begin{array}{c}\text { Group II } \\
(n=30)\end{array} \\
\end{array}$ & $\begin{array}{c}\text { Group III } \\
(n=30)\end{array}$ \\
\hline Total cholesterol (mg/dl) & $142.63 \pm 1.73$ & $158.13 \pm 41.97$ & $169.53 \pm 41.2^{\mathrm{a}}$ \\
\hline HDL-cholesterol (mg/dl) & $36.5 \pm 7.0$ & $35.5 \pm 10.33$ & $37.43 \pm 7.29$ \\
\hline LDL-cholesterol (mg/dl) & $88.07 \pm 20.12$ & $95.50 \pm 38.5$ & $94.6 \pm 35.5$ \\
\hline Triglycerides (mg/dl) & $104.4 \pm 44.4$ & $125.7 \pm 56.0$ & $178.56 \pm 82.6^{\mathrm{a}, \mathrm{b}}$ \\
\hline
\end{tabular}




Table 3: Comparison of Apo-B, Apo-A and
\begin{tabular}{lccc} 
Apo-B/A1 ratio in the study groups (mean \pm SD) \\
\hline Parameter & $\begin{array}{c}\text { Group I } \\
(\mathbf{n}=\mathbf{3 0})\end{array}$ & $\begin{array}{c}\text { Group II } \\
(\mathbf{n}=\mathbf{3 0})\end{array}$ & $\begin{array}{c}\text { Group III } \\
(\mathbf{n}=\mathbf{3 0})\end{array}$ \\
\hline Apo-B $(\mathrm{mg} / \mathrm{dl})$ & $90.37 \pm 17.00$ & $111.37 \pm 27.04^{\mathrm{a}}$ & $119.63 \pm 24.62^{\mathrm{b}}$ \\
Apo-A $(\mathrm{mg} / \mathrm{dl})$ & $141.27 \pm 28.2$ & $97.47 \pm 19.05^{\mathrm{a}}$ & $86.7 \pm 31.86^{\mathrm{b}}$ \\
Apo-B/A1 & $0.66 \pm 0.15$ & $1.20 \pm 0.36^{\mathrm{a}}$ & $1.48 \pm 0.51^{\mathrm{b}}$ \\
\hline Where, ${ }^{\mathrm{a} G r o u p ~ 1 ~ v s . ~ G r o u p ~ 2 ~}(\mathrm{p}<0.001) ;{ }^{\mathrm{b} G r o u p ~ 1 ~ v s . ~ G r o u p ~ 3 ~}(\mathrm{p}<0.001)$
\end{tabular}

in group 2 (non-obese) and group 3 (obese) as compared group 1 (controls), whereas insignificant level was found in group 3 as compared to in group 2 (Table 3).

Apo-B/A1 ratio was significantly higher $(p<.001)$ in non obese and obsese patients as compared to control whereas insignificant difference of ratio was found between obese and non obese patients (Table 3).

\section{DISCUSSION}

Plasma levels of TC and LDL-C are correlated with prevalence of CAD. ${ }^{16}$ High levels of LDL-C predisposes to premature CAD. ${ }^{17}$ Still many patients with $\mathrm{CAD}$ do not have elevated LDL-C or other detectable lipoprotein lipid level. ${ }^{18}$ Many patients with advanced coronary atherosclerosis have elevated levels of Apo B but normal LDL-C. ${ }^{18}$ Patients with premature coronary heart disease (CHD) have over production of LDL-apo B and yet normal concentration of LDL-C, enhanced production of LDLapo B may cause accelerated atherosclerosis. ${ }^{18}$ There are three major components of the dyslipidemia that occur in obesity: increased fasting and postprandial triglyceride-rich lipoproteins (TRLs), decreased HDL and increased small dense LDL particles. There is also evidence from case control studies that apoB and apo A1 may be superior to LDL and HDL in discriminating Ischemic heart disease (IHD) case subjects. ${ }^{18}$ In the present study, levels of HDL-C and LDL-C were found insignificant. We also found that levels of TG and total cholesterol were highly significant in obese patients as compared to non-obese and controls whereas non significant levels of total cholesterol was found in non obese patients as compared to obese and controls.

Many researchers found that apoliproteins are the better predictors found of risk for CAD as compared to controls. Apo-B synthesis is required for the hepatic secretion of VLDL and Apo-B remains associated with particle during the triglycerides hydrolysis and lipid exchange cascade until its clearance from the circulation as LDL or IDL particles. There is abundance of evidence from case control reports to support the role of Apo-B as an important risk factor for IHD. ${ }^{19}$ In our study Apo-B was highly significant in non obese and obese patients of CAD as compared to controls whereas Apo-B levels are not significant in obese patients as compared to non-obese patients. High numbers of Apo-B containing lipoproteins will results in the presence of an elevated number of small dense LDL particles which have been associated with an enhanced risk of CAD. ${ }^{20}$ There may also an increased secretion of VLDL apo-B particles synthesis, a condition that may favour the formation of small, dense, atherogenic LDL particles. ${ }^{20-22}$ The range of values for apoB secretion among the obese was wide and partly related to central adiposity, insulin resistance and genetic factors. ${ }^{23-25}$ Increase in Apo-B in non-obese patients could be because of other pathophysiological abnormalities and associated risk factor that could lead to formation of small dense LDL. These works suggest that abnormalities in metabolism of Apo-B which are not necessarily revealed by concentration of LDL-C may cause acceleration of atherosclerosis.

It has been suggested that Apo-A1 measurements may provide more information then HDL cholesterol levels in the assessment of ischemic heart disease risk. ${ }^{26}$ Levels of apo A-I are strongly correlated with those of HDL-C, and expression of apo A-I may be largely responsible for determining the plasma level of HDL. Apo A-I also acts as a cofactor for lecithin cholesterol acyl transferase (LCAT) which is important in removing excess cholesterol from tissues and incorporating it into HDL for reverse transport to the liver. Furthermore, apo A-I is the ligand for the ATP-binding cassette $(\mathrm{ABC})$ protein, $\mathrm{ABCA1}$ and hence is involved in the docking procedure by which excess cholesterol in peripheral cells is externalized to HDL for further reverse cholesterol transport either directly or indirectly via LDL back to the liver. ApoA-I also manifests anti-inflammatory and antioxidant effects. ${ }^{27}$ The anti-atherogenic properties of apoA-I were recently documented..$^{28}$ In our study, Apo-A1 was significantly decreased in non obese and obese compared to controls whereas Apo-A1 levels were not significantly decreased in obese patients as compared to non-obese patients of CAD.

The ratio of Apo-B/ApoA1 has also suggested that predicating of the severity of CAD. ${ }^{29}$ The two largest of these studies are the AMORIS ${ }^{30}$ and the INTERHEART ${ }^{31}$ studies which both show a very strong direct relation between a high apoB/apoA-I ratio and an increased risk of fatal $\mathrm{MI}^{7}$ and acute MI (AMI). ${ }^{9}$ These results are in line with the findings in the INTERHEART study, which was based on almost 15000 AMI compared with 15000 age- and sex-matched controls. ${ }^{31}$ In that study the apoB/A-1 ratio was the strongest of all risk factors including smoking, hypertension, abdominal obesity, diabetes, alcohol, psycho-social stress, vitamin intake, and exercise. The results were independent of age, gender, and ethnicity. Furthermore, the apo B/A1 ratio also 
remained the strongest of all risk factors in multivariate analyses. ${ }^{31}$ Our study showed that Apo-B/Apo-A1 ratio are significant in non-obese and obese patients of $\mathrm{CAD}$ as compared to controls whereas Apo-B,/Apo-A1 ratio were not significantly changed in obese as compared to non obese.

\section{CONCLUSION}

These findings suggest that increase in concentration of Apo B and decrease Apo A1 can be considered to be risk factor for CAD in cases of normolipidemic profile where HDL-C and LDL cholesterol are not significantly changed in study population. Both obese and non obese patients showed increase in ApoB, Apo A1 ratio and non significant difference between these two groups. Therefore, altered levels of apolipoproteins are independent risk factor of CAD irrespective of obesity and early assessment of apolipoproteins (Apo-B, apo-A1, Apo-B/Apo-A1 ratio) can be effective in prediction of CAD complications.

\section{REFERENCES}

1. Sarvotham SG and Berry JN. Prevalence of coronary artery disease in urban population in Northern India. Circulation 1968; 37: 939-953.

2. Raman Kutty V, Balakrishnan KG, Jayasree AK and Thomas J. Prevalence of coronary heart disease in the rural population of Thiruvananthapuram district, Kerala, India. Int J Cardiol 1993; 39: 59-70.

3. Chadha SL, Radhakrishnan S, Ramachandran K, Kaul U and Gopinath N. Epidemiological study of coronary heart disease in urban population of Delhi, India. J Med Res 1990; 92:424-430.

4. Das D, Saxena R and Bhattacharya I. Alteration in plasma paraoxonase levels and its relation with Coronary Artery Disease. Sch J App Med Sci 2014; 2(5C): 1682-1687.

5. Saxena R and Mehrotra V. Prediction of hypertension and cardiovascular disease risk in North Indian geriatric population: a conundrum of senescence. Int J Comm Med Public Health 2014; 1(1): 18-23.

6. Mokdad AH, Ford ES, Bowman BA, Dietz WH, Vinicor F, Bales VS, et al. Prevalence of obesity, diabetes, and obesityrelated health risk factors. JAMA 2003; 289: 76-79.

7. Rexrode KM, Carey VJ, Hennekens CH, Walters EE, Colditz GA, Stampfer MJ, et al. Abdominal adiposity and coronary heart disease in women. JAMA 1998; 280: 1843-1848.

8. Grundy SM, Cleeman JI, Merz CN, Brewer HB, Clark LT and Hunninghake DB. National Heart, Lung and Blood Institute; American College of Cardiology Foundation; American Heart Association. Implications of recent clinical trials for the National Cholesterol Education Program Adult Treatment Panel III guidelines. Circulation 2004; 110: 227-239.

9. Walldius G, Jungner I, Holme I, Aastveit AH, Kolar W and Steiner E. High apolipoprotein B, low apolipoprotein A-I, and improvement in the prediction of fatal myocardial infarction (AMORIS study): a prospective study. Lancet 2001; 358: 2026-2033.

10. Avogaro P, Bon GB, Gazzolato G and Quinci GB. Are apolipoproteins better discriminators than lipids for atherosclerosis? Lancet 1979;1: 901-903.

11. Maciejko JJ, Holmes DR, Kottke BA, Zinsmeister AR, Dinh DM and Mao SJ. Apolipoprotein A-I as a marker of angiographically assessed coronary artery disease. N Engl J Med 1983; 309: 385-389.

12. Wald NJ, Law M, Watt HC, Wu T, Bailey A, Johnson AM, et al. Apolipoproteins and ischaemic heart disease: implications for screening. Lancet 1994; 343: 75-79.

13. Lamarche B, Moorjani S, Lupien PJ, Cantin B, Bernard PM, Dagenais GR, et al. Apolipoprotein A-I and B levels and the risk of ischemic heart disease during a five-year follow-up of men in the Que'bec Cardiovascular Study. Circulation 1996; 94: 273-278.

14. Sigurdsson G, Baldursdottir A, Sigvaldason H, Agnarsson U, Thorgeirsson $G$ and Sigfusson N. Predictive value of apolipoproteins in a prospective survey of coronary artery disease in men. Am J Cardiol 1992; 69: 1251-1254.

15. Stampfer MJ, Sacks FM, Salvini S, Willett WC and Hennekens $\mathrm{CH}$. A prospective study of cholesterol, apolipoproteins and the risk of myocardial infarction. $\mathrm{N}$ Engl $\mathrm{J}$ Med 1991; 325: 373-381.

16. Wilson PW, Garrison RJ, Castelli WP, Feinleib U, McNamara PM and Kannel WB. Prevalence of coronary heart disease in the Framingham offspring study: study of lipoprotein cholesterols. Am J Cardiol 1980; 46: 649-654.

17. Gordon T, Castelli W P, Hjortland MC, Kanne W B and Dawber TR. Predicting coronary heart disease in middle-aged and older persons- The Framingham study. J Am Med Assoc 1977; 238: 497-499.

18. Sniderman AS, Shapiro D, Marpole B, Skinner BT and Kwiterovich PO. Association of coronary atherosclerosis with hyperapobetalipoproteinemia. Proc Natl Acad Sci 1980; 77: 604- 608.

19. Lamarche B, Moorjani S, Lupien PJ, Cantin B, Bernard PM, Dagenais GR, et al. Apolipoprotein A-I and B levels and the risk of ischemic heart disease during a five-year follow-up of men in the Quebec Cardiovascular Study. Circulation 1996; 94: 273-278.

20. Austin MA, King MC, Vranizan KM and Krauss RM. Atherogenic lipoprotein phenotype: a proposed genetic marker for coronary heart disease risk. Circulation 1990; 82: 795-506.

21. Kesaniemi YA and Grundy SM. Overproduction of lowdensity lipoproteins associated with coronary heart disease. Arteriosclerosis 1983; 3: 40-46.

22. Kwiterovich $P O$ and Sniderman $A D$. Atherosclerosis and apopoprteins B and A-I. Prevent Med 1983; 12: 815-834

23. Watts GF, Riches FM, Kelly JM, Powell MA, Croft and KD. Determinants of the kinetics of very low-density lipoprotein apolipoprotein B-100 in non-obese men. Clin Exp Pharmacol Physiol 1997; 24: 556-562.

24. Riches FM, Watts GF, Naoumova RP, Kelly JM, Croft KD and Thompson GR. Hepatic secretion of very-low-density lipoprotein apolipoprotein B-100 studied with a stable isotope technique in men with visceral obesity. Int J Obes Relat Metab Disord 1998; 22: 414-423.

25. Watts GF, Riches FM, Humphries SE, Talmund PJ and Van Bockxmeer FM. Genotypic associations of the hepatic secretion of VLDL apolipoprotein B-100 in obesity. J Lipid Res 2000; 41: 481-488.

26. Stampfer MJ, Sacks FM, Salvini S, Willet WC and Hennekens $\mathrm{CH}$. A prospective study of cholesterol, apolipoproteins, and the risk of myocardial infarction. N Engl J Med 1991; 325: 373-381.

27. Walldius $G$ and Jungner I. Apolipoprotein B and apolipoprotein A-I: risk indicators of coronary heart disease and targets for lipidmodifying therapy. J Intern Med 2004; 255:188-205. 
28. Nissen SE, Tsunoda T, Tuzcu EM, Schoenhagen P, Cooper CJ, Yasin M, et al. Effect of recombinant ApoA-I milano on coronary atherosclerosis in patients with acute coronary syndromes: a randomized controlled trial. JAMA 2003; 290:2292-2300.

29. Sedlis SP, Shechtman KB, Ludbrook PA, Sobel BE and Schonfeld G. Plasma apoproteins and the severity of coronary artery disease. Circulation 1986; 73: 978-986.

30. Walldius G, Jungner I, Holme I, AastveitAH, KolarW and SteinerE.
High apolipoprotein B, low apolipoprotein A-I, and improvement in the prediction of fatal myocardial infarction (AMORIS study): a prospective study. Lancet 2001;358:2026-2033.

31. Yusuf S, Hawken S, Ounpuu S, Dans T, Avezum A, Lanas F, McQueen $M$, et al. Effect of potentially modifiablerisk factors associated with myocardial infarction in 52 countries (the INTERHEART study): case-control study. Lancet 2004; 364: 937-952.

\section{Authors Contribution:}

S - Biochemical analysis, Data collection; SBS - Principal investigator, Planning \& Formulation of study; SD - Facilitate the sample collection, Manuscript Editing; MS - Evaluation and Literature search; RS - Preparation of manuscript, Manuscript editing, Statistical analysis, Literature search.

Source of Support: Nil. Conflict of Interest: None. 